\title{
Estudo farmacobotânico de folhas de Cissampelos sympodialis Eichl. (Menispermaceae)
}

\author{
Niara Moura Porto, Ionaldo José Lima Diniz Basílio, Maria de Fátima Agra* \\ Laboratório de Tecnologia Farmacêutica "Delby Fernandes de Medeiros", Universidade Federal da Paraíba, \\ Caixa Postal 5009, 58015-970 João Pessoa-PB, Brasil
}

\begin{abstract}
RESUMO: Cissampelos sympodialis Eichl. é uma espécie empregada na medicina popular do Nordeste do Brasil, cujos estudos farmacológicos são bastantes promissores no tratamento de doenças do trato respiratório. Neste trabalho realizou-se um estudo farmacobotânico de suas folhas, com o objetivo de elaborar morfodiagnoses macroscópicas e microscópicas que auxiliem sua caracterização. Realizaram-se secções paradérmicas (lâminas) e transversais de folhas (lâmina e pecíolo), posteriormente clarificadas e coradas com safranina e safrablue, respectivamente, e observadas ao microscópio óptico. Cissampelos sympodialis caracteriza-se pelas folhas peltadas, com as lâminas deltóides, nervação actinodroma-broquidodroma, e o pecíolo espessado nas extremidades. A epiderme é hipoestomática, com células de paredes anticlinais ondeadas na face adaxial e irregularmente sinuosa a ondeada na abaxial. O mesofilo é dorsiventral e o sistema vascular do pecíolo é formado de um anel de feixes isolados colaterais. Esparsos idioblastos de cristais prismáticos foram observados no parênquima peciolar. A morfologia foliar em conjunto com a anatomia da epiderme são caracteres distintivos para Cissampelos sympodialis.
\end{abstract}

Unitermos: Menispermaceae, Cissampelos sympodialis, morfo-anatomia, plantas medicinais.

\begin{abstract}
Pharmacobotanical study of the leaves of Cissampelos sympodialis Eichl., (Menispermaceae)". Cissampelos sympodialis Eichl. is a plant species used in popular medicine in Northeast of Brazil, whose pharmacological studies are very promising in the treatment of diseases of the respiratory tract. In this work, a pharmacobotanical study of the leaves was performed with the objective to elaborate a macroscopical and microscopical morphodiagnosis to support its characterization. The microscopical morphodiagnosis was done with paradermic sections on the blades and cross sections on the blades and petioles followed by clarification and coloring with safranin and safrablue, respectively, and examined by optical microscopy. Cissampelos sympodialis has peltate leaves with deltoid blades with actinodromous -brochidodromous nervation, and the petioles are swollen at the extremities. The epidermis is hipostomatic with anticlinal walls of epidermal cells waved in the upper surface and irregularly sinuate to wavy on the lower surface. The mesophyll is dorsiventral and the vascular system of the petiole is formed by a ring of 6-7 free collateral bundles. Sparce idioblasts of prismatic crystals in parenchyma of petiole were observed. The morphology of the leaves and the anatomy of epidermis are distinguishing characters of Cissampelos sympodialis.
\end{abstract}

Keywords: Menispermaceae, Cissampelos sympodialis, morpho-anatomy, medicinal plants.

\section{INTRODUÇ̃̃O}

A família Menispermaceae DC. está constituída de 70 gêneros e cerca de 420 espécies, predominantemente tropicais (Stevens, 2001). No Brasil, está representada por cerca de 12 gêneros e 106 espécies, tendo a Amazônia como seu maior centro de distribuição (Krukoff \& Barneby, 1970). A família ficou bastante conhecida, principalmente, pelos estudos químicos e farmacológicos com espécies de Chondodrendron, que são usadas na preparação de curare (Bisset, 1988).

De acordo com Rhodes (1975), o gênero Cissampelos L. possui 19 espécies distribuídas na América tropical, África e Ásia. Estudos filogenéticos mais recentes (Wang et al., 2007) têm apoiado a posição do gênero na tribo Menispermae, como membro da subtribo Cissampelinae, cuja monofilia da tribo também é fortalecida por caracteres morfológicos, incluindo formas e tipos de grãos de pólen.

Cissampelos sympodialis Eichl. é uma espécie da flora brasileira, encontrada desde o Ceará até o norte de Minas Gerais, ocorrendo principalmente em áreas de semi-árido (Rhodes, 1975). A espécie é conhecida popularmente como "milona", "jarrinha", "orelha-deonça" e "abuteira", cujas folhas e raízes são empregadas na medicina popular no tratamento de doenças do aparelho respiratório, reumatismos e artrites (BarbosaFilho et al., 1997; Agra et al., 2007a,b). 
Do ponto de vista químico, vários alcalóides isoquinolínicos foram isolados de Cissampelos sympodialis, dentre os quais destacam-se: milonina (Freitas et al., 1995), warifteína (Cortes et al., 1995), metilwarifteína e laurifolina(Barbosa-Filho et al., 1997), liriodenina e roraimina (Lira et al., 2002).

É uma espécie de grande importância na farmacologia pelas diversas atividades já confirmadas, como espasmolítica e efeito citotóxico, atribuídos a warifteína e a milonina (Freitas et al., 1996; Melo et al., 2003), anti-anafilática (Thomas et al., 1997), antidepressiva (Almeida et al., 1998), antiinflamatória (Lima et al., 2001; Falcão et al., 2005) que em parte esta relacionada à diminuição da função dos macrófagos (Alexandre-Moreira et al., 2003). Além disso, foi demonstrado que o tratamento oral com o extrato etanólico de suas folhas apresentaram um efeito imunomodulador (Bezerra-Santos et al., 2004) e que a warifteína é um componente ativo do extrato de $C$. sympodialis responsável por uma ação antialérgica (Bezerra-Santos et al., 2006).

Realizou-se um estudo morfo-anatômico de folhas de Cissampelos sympodialis, com o objetivo de elaborar morfodiagnoses macroscópica e microscópica que forneçam subsídios à sua caracterização, dando continuidade aos estudos farmacobotânicos das espécies de uso medicinal na Paraíba (Agra et al., 2007b; Barbosa et al., 2007; Coelho et al., 2006; Coutinho et al., 2006a,b; Basílio et al. 2006; Silva \& Agra, 2005).

\section{MATERIAL E MÉTODOS}

O material botânico foi coletado de plantas cultivadas no Horto do Laboratório de Tecnologia Farmacêutica "Prof. Delby Fernandes Medeiros", Universidade Federal da Paraíba, João Pessoa, Brasil, em março e abril de 2007. Amostras herborizadas estão depositadas no herbário Lauro Pires Xavier, Universidade Federal da Paraíba.

A identificação da espécie e a morfodiagnose macroscópica de folhas foram realizadas após estudos morfológicos em amostras frescas e exsicatas do herbário JPB, com o auxílio da bibliografia (Eichler, 1864; Krukoff \& Barneby, 1970; Rhodes, 1975; Barbosa-Filho et al., 1997) e estereomicroscópio binocular, Zeiss.

Para a morfodiagnose microscópica realizaram-se secções transversais (lâmina foliar e pecíolo) e paradérmicas (adaxial e abaxial), à mão livre, com lâmina cortante, em folhas adultas, coletadas no $5^{\circ}$ nó. Posteriormente, as secções foram clarificadas com hipoclorito de sódio a $20 \%$, neutralizadas com água acética $0,2 \%$, lavadas em água destilada, coradas com uma solução de safrablue e safranina, respectivamente, montadas entre lâmina e lamínula com glicerina a 50\%, e analisadas ao microscópio óptico.

As caracterizações das paredes celulares da epiderme e do mesofilo basearam-se em Fahn (1990) e a classificação dos estômatos seguiu Metcalfe \& Chalk (1979). As abreviaturas dos autores seguem Brummitt \& Powell (1992).

As estruturas foram observadas e fotomicrografadas ao microscópio óptico, Olympus, modelo CX31, com câmara fotográfica Olympus PMBP35.

\section{RESULTADOS}

\section{Morfodiagnose macroscópica}

Folhas alternas, pecioladas; lâmina 2,0-6,0 x 1,5-6,5 cm, oval a deltóide, glabra, margens inteiras, ápice obtuso a agudo, base truncada, discolor, face adaxial brilhante, verde-escuro (Figura 1), face abaxial opaca, verde-claro (Figura 2), nervação do tipo actinódromo-broquidódromo, com 7-11 nervuras, proeminentes na face abaxial, e impressas na adaxial (Figuras 1-2); pecíolo reto, peltado, excêntrico, 2,0-4,0 x 0,1-0,2 cm, cilíndrico, com ápice e base alargados e levemente curvados (Figura 2), pubérulo, tricomas simples, pluricelulares, unisseriados.

\section{Morfodiagnose microscópica}

Em vista frontal, a epiderme de Cissampelos sympodialis é hipoestomática, com estômatos do tipo anomocítico e paredes celulares anticlinais ondeadas, delgadas na face adaxial (Figura 3), maiores e sinuosas a ondeadas na face abaxial (Figura 4). Em secção transversal, a epiderme é unisseriada, com paredes periclinais irregulares e convexas, revestida por uma cutícula lisa e delgada, em ambas as faces. Na face abaxial, os estômatos estão situados no mesmo nível das células epidérmicas (Figura 5).

O mesofilo possui organização dorsiventral, com parênquima paliçádico uni-estratificado e o parênquima esponjoso 4-6-estratificado. Feixes vasculares do tipo colateral, envolvidos por uma bainha parenquimática distribuem-se ao longo do mesofilo (Figura 5).

O bordo da lâmina, em seção transversal, é rotundo e ligeiramente revoluto, com a epiderme uniestratificada, seguida do colênquima multiestratificado e de pequenos feixes vasculares circundados por células esclerenquimáticas (Figura 6).

A nervura principal é biconvexa, com apenas um feixe central do tipo colateral, circular. O colênquima subepidérmico é do tipo lacunar, 3-5-estratificado, seguido do parênquima fundamental (Figura 7).

O pecíolo, em secção transversal (Figura 8), exibe contorno circular a semicircular, com a epiderme uniestratificada, seguida de colênquima lacunar subepidérmico (Figura 11), e de um anel de esclerênquima circundando os feixes vasculares (Figura 8) desde a porção proximal até o inicio do espessamento 

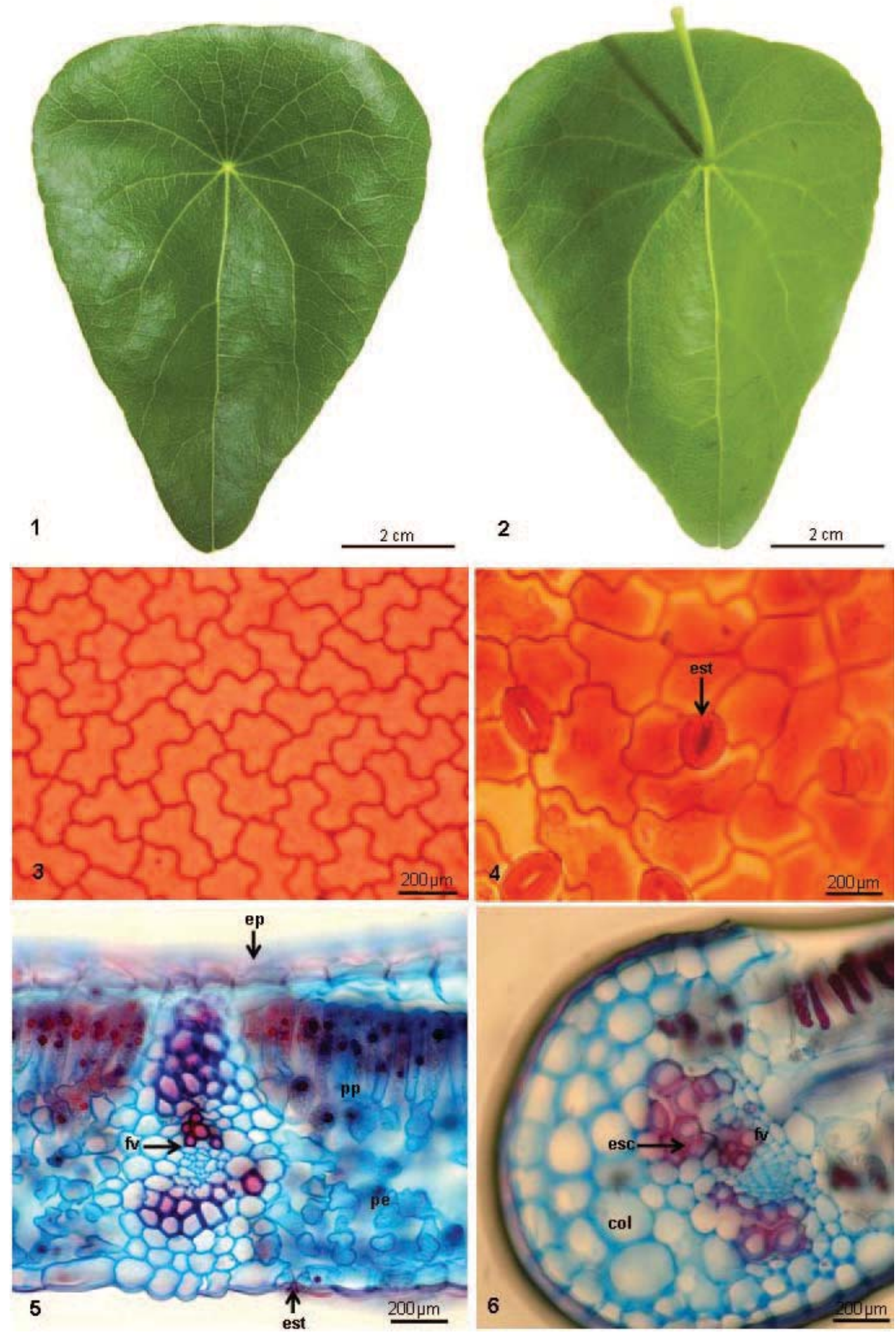

Figuras 1-6. Folhas de Cissampelos sympodialis Eichl. (Agra et al. 6895). 1. Face adaxial: nervação actinódromobroquidódromo; 2. Face abaxial, pecíolo excêntrico; 3-4. Epiderme, vista frontal: 3. Paredes celulares ondeadas, face adaxial; 4. Paredes celulares sinuosas a ondeadas e estômatos anomocíticos, face abaxial; 5. Seção transversal da lâmina: mesofilo assimétrico, detalhe do feixe vascular (fv) e estômatos ao nível da epiderme; 6. Seção transversal do bordo, detalhe do feixe vascular circundado pelo esclerênquima. Legendas: colênquima (col), esclerênquima (esc), estômatos (est), feixe vascular (fv), parênquima esponjoso (pe), parênquima paliçadico (pp). 

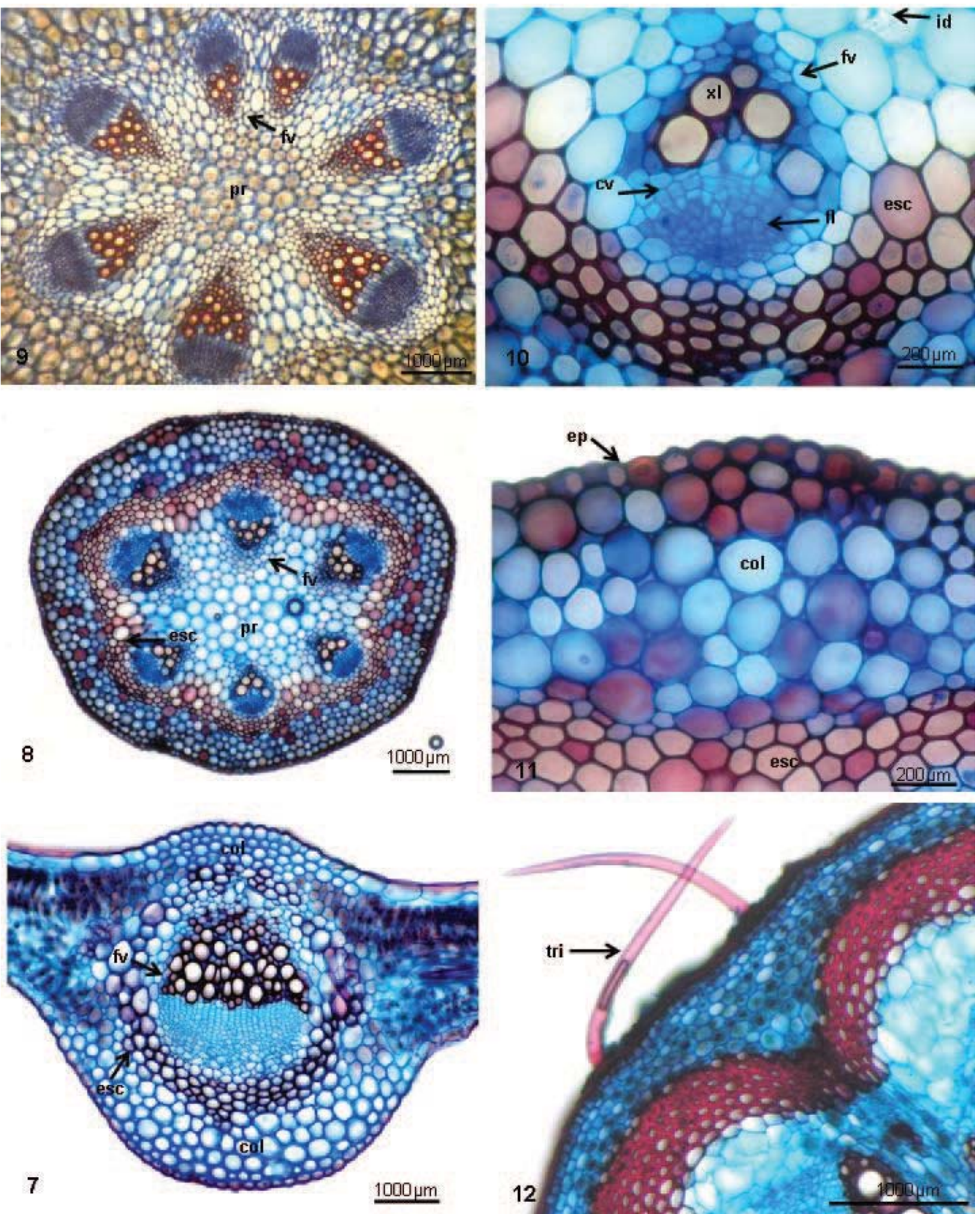

Figuras 7-12. Cissampelos sympodialis Eichl. (Agra et al. 6895). 7. Nervura mediana, em seção transversal: feixe vascular central; 8-11. Pecíolo, em seção transversal; 8. Porção mediana: 6-feixes vasculares, livres, circundado por um arco esclerenquimático; 9. Pecíolo, porção distal: 7-feixes vasculares, livres, desprovidos de arco esclerenquimático; 10 . Detalhe do feixe vascular colateral; 11. Detalhe da epiderme, colênquima e esclerênquima; 12. Detalhe do arco esclerenquimático e da epiderme com tricomas simples. Legendas: câmbio vascular (cv), colênquima (col), epiderme (ep), esclerênquima (esc), feixe vascular (fv), floema (fl), idioblastos (id), parênquima (pr), tricomas (tri), xilema (xl). 
da porção distal, não sendo observado nesta porção (Figura 9). O sistema vascular é formado por seis feixes colaterais (Figura 8), ovóides, dispostos em círculo das porções proximal e mediana, e sete feixes na porção mediana e distal (Figura 9), o floema é multisseriado, seguido do câmbio vascular, 3-5-estratificado e do xilema com elementos de vasos dispostos radialmente (Figura 10). Raros e esparsos tricomas simples, unisseriados, foram observados na epiderme (Figura 12).

\section{Material examinado}

BRASIL. Paraíba: João Pessoa, 23/IV/1992 (fl), MF Agra 1497 (JPB); João Pessoa, 23/IV/1992 (fl), MF Agra 1139 (JPB); João Pessoa, 10/04/2007 (estéril), MF Agra et al. 6895 (JPB).

\section{DISCUSSÃO}

A epiderme foliar hipoestomática com estômatos anomocíticos, observada em Cissampelos sympodialis, é uma característica também referida por Metcalfe \& Chalk (1979) para duas outras espécies de Cissampelos e por Hong et al. (2001), para 29 gêneros de Menispermaceae, inclusive da tribo Menispermeae, subtribo Cissampelinae à qual o gênero Cissampelos está subordinado. Entretanto, difere do tipo anfiestomático, descrito por Metcalfe \& Chalk (1979) para duas espécies de Cocculus da subtribo Cocculeae.

Em Cissampelos sympodialis, as células epidérmicas com paredes anticlinais ondeadas na face adaxial e irregularmente sinuosa-ondeada na face abaxial é um caráter distintivo para esta espécie, distinguindo-a de $C$. pareira L., espécie com a qual compartilha vários caracteres, inclusive a ausência de papilas na epiderme, característica comum em Cissampelos capensis L. f. e C. glaberrima A.St-Hil., que possuem papilas na face abaxial, com base em Metcalfe \& Chalk (1979) e Hong et al. (2001).

Com relação ao mesofilo (dorsiventral) e à vascularização (do tipo colateral), os padrões observados correspondem aos tipos descrito por Metcalfe \& Chalk (1979). A presença de idioblastos com diminutos cristais prismáticos observado em células parenquimáticas do pecíolo é um caráter registrado para vários gêneros da tribo Menispermeae, como Cyclae, Diploclisia, Stephania e Cissampelos, entre outros. (Metcalfe \& Chalk, 1979; Wang et al. 2007).

A presença de sacos secretores associados ao arco esclerenquimático, geralmente presente no feixe vascular e no pecíolo, registrado para várias espécies de Menispermaceae, inclusive em Cissampelos pareira L. e Cissampelos fasciculata Benth. (Metcalfe \& Chalk, 1979) é um caráter não observado em Cissampelos sympodialis.

\section{CONCLUSÃO}

A morfologia da folha com a lâmina foliar, deltóide, e o pecíolo espessado nas extremidades em conjunto com a anatomia da epiderme, com células epidérmicas de paredes anticlinais ondeadas na face adaxial e irregularmente sinuosa-ondeada na face abaxial, e a ausência de sacos secretores são caracteres diagnósticos para Cissampelos simpodialis.

\section{AGRADECIMENTOS}

Os autores agradecem ao Conselho Nacional de Pesquisas e Desenvolvimento $(\mathrm{CNPq})$ pelas bolsas concedidas a Ionaldo José Lima Diniz Basílio (MSc.) e Maria de Fátima Agra (PQ); ao Dr. Jnanabrata Bhattacharyya, pela revisão do abstract; à Kiriaki Nurit pelo apoio e sugestões; à Dulce G. Oliveira, pelo apoio técnico.

\section{REFERÊNCIAS}

Agra MF, França PF, Barbosa-Filho JM 2007a. Synopsis of the plants known as medicinal and poisonous in Northeast of Brazil. Rev Bras Farmacogn 17: 114-140.

Agra MF, Nurit-Silva K, Baracho GS, Basílio, IJLD 2007 b. Estudo farmacobotânico de folhas de Nicotiana glauca (Solanaceae). Lat Am J Pharm 26: 499-506.

Alexandre-Moreira MS, Freire-de-Lima CG, Trindade MN, Castro-Faria-Neto HC, Piuvezam MR, Peçanha LMT 2003. Modulation of B lymphocyte function by an aqueous fraction of the ethanol extract of Cissampelos sympodialis Eichl. (Menispermaceae). Braz J Med Biol Res 36: 199-205.

Almeida RN, Navarro DS, Assis TS, Medeiros IA, Thomas G 1998. Antidepressant effect of an ethanolic extract of the leaves of Cissampelos sympodialis in rats and mice. J Ethnopharmacol 63: 247-252.

Barbosa DA, Silva KN, Agra MF 2007. Estudo farmacobotânico comparativo de folhas de Turnera chamaedrifolia Cambess. e Turnera subulata Sm. (Turneraceae). Rev Bras Farmacogn 17: 396-413.

Barbosa-Filho JM, Agra MF, Thomas G 1997. Botanical, chemical and pharmacological investigation on Cissampelos species from Paraíba (Brazil). J Braz Assoc Advanc Sci 49: 386-394.

Basílio IJLD, Agra MF, Rocha EA, Leal CKA, Abrantes, HFL 2006. Estudo farmacobotânico comparativo das folhas de Hyptis pectinata (L.) Poit. e Hyptis suaveolens (L.) Poit. (Lamiaceae). Acta Farm Bonaerense 25: 518-525.

Bezerra-Santos CR, Balestieri FMP, Rossi-Bergmann B, Peçanha LMT, Piuvezam MR 2004. Cissampelos sympodialis Eichl. (Menispermaceae): oral treatment decreases IgE levels and induces a Th1-skewed cytokine production in ovalbumin-sensitized mice. $J$ Ethnopharmacol 95: 191-197.

Bezerra-Santos CR, Vieira-de-Abreu A, Barbosa-Filho 
JM, Bandeira-Melo C, Piuvezam MR, Bozza PT 2006. Anti-allergic properties of Cissampelos sympodialis and its isolated alkaloid warifteine. Int Immunopharmacol 6: 1152-1160.

Bisset NG 1988. Curare-botany, chemistry, and pharmacology. Acta Amazonica 18: 255-290.

Brummit RK, Powell CE 1992. Authors of Plant Names. Kew: Editora Royal Botanic Gardens.

Coelho VPM, Agra MF, Barbosa MRV 2006. Estudo farmacobotânico das folhas de Tocoyena formosa (Cham. \& Schltdl.) K.Schum. (Rubiaceae). Rev Bras Farmacogn 16: 170-177.

Cortes SF, Alencar JL, Thomas G, Barbosa-Filho JM 1995. Spasmolytic actions of warifteine, a bisbenzylisoquinoline alkaloid isolated from the root bark of Cissampelos sympodialis Eichl. (Menispermaceae). Phytother Res 9: 579-583.

Coutinho DF, Agra MF, Barbosa-Filho JM, Basílio IJLD 2006a. Morfo-anatomia foliar de Ocotea gardneri (Meisn.) Mez (Lauraceae-Lauroideae). Rev Bras Farmacogn 16: 178-184.

Coutinho DF, Agra MF, Basílio IJLD, Barbosa-Filho JM 2006b. Morphoanatomical study of the leaves of Ocotea duckei Vattimo (Lauraceae-Lauroideae). Rev Bras Farmacogn 16: 537-544.

Eichler AW 1864. Menispermaceae. In: P. Martius (ed.). Fl Bras 13: 161-196.

Fahn A 1990. Plant Anatomy. 4.ed. New York: Editora Pergamon Press.

Falcão HS, Lima IO, Santos VL, Dantas HF, Diniz MFFM, Barbosa-Filho JM, Batista LM 2005. Review of the plants with anti-inflammatory activity studied in Brazil. Rev Bras Farmacogn 15: 381-391.

Freitas MR, Alencar JL, Cunha EVL, BarbosaFilho JM, Gray AI 1995. Milonine, a novel 8,14-dihydromorphinandienone alkaloid from leaves of Cissampelos sympodialis. Phytochemistry 40: 1553-1555.

Freitas MR, Cortes SF, Thomas G, Barbosa-Filho JM 1996. Modification of $\mathrm{Ca}^{2+}$ metabolism in the rabbit aorta as a mechanism of spasmolytic action of wariftein, a bisbenzylisoquinoline alkaloid isolated from the leaves of C. sympodialis Eichl. (Menispermaceae). $J$ Pharm Pharmacol 48: 333-336.

Hong Y, Pan K, Chen Z, Lu A 2001. Characters of leaf epidermis and their systematic significance in Menispermaceae. Acta Bot Sin 43: 615-623.

Krukoff BA, Barneby RC 1970. Suplementary notes on American Menispermaceae - VI. Mem New York Bot Gard 20: 1-70.

Lima KVB, Ribeiro R, Balestieri FMP, Thomas G, Piuvezam MR 2001. Anti-inflammatory activity of Cissampelos sympodialis Eichl. (Menispermaceae) leaf extract. Acta Farm Bonaerense 20: 275-279.

Lira GA, Andrade LM, Florêncio KC, Silva MS, BarbosaFilho JM, Cunha EVL 2002. Roraimine: a bisbenzylisoquinoline alkaloid from Cissampelos sympodialis roots. Fitoterapia 73: 356-358.

Melo PS, Cavalcante HMM, Barbosa-Filho JM, Diniz MFFM, Medeiros IA, Haun M 2003. Warifteine and milonine, alkaloids isolated from Cissampelos sympodialis Eichl: cytotoxicity on rat hepatocyte culture and in V79 cells. Toxicol Lett 142: 143-151.

Metcalfe CR, Chalk L 1979. Anatomy of the Dicotyledons. 2.ed. v.1. Oxford: Editora Claredon Press.

Rhodes DG 1975. A revision of the genus Cissampelos. Phytol 30: 415-485.

Silva KN, Agra MF 2005. Estudo farmacobotânico comparativo entre Nicandra physalodes (L.) Gaertn. e Physalis angulata L. (Solanaceae). Rev Bras Farmacogn 15: 344-351.

Stevens PF 2001. Angiosperm Phylogeny Website. Version 8, June 2007. http:// www.mobot.org/MOBOT/ research/APweb/.

Thomas G, Araújo CC, Duarte JC, Souza DP 1997. Bronchodilatory activity of an aqueous fraction of the ethanolic extract of the leaves of Cissampelos sympodialis Eichl. (Menispermaceae) in guinea-pig. Phytomedicine 4: 233-238.

Wang W, Heng-Ghang W, Zhi-Duan C 2007. Phylogeny and morphological evolution of tribe Menispermeae (Menispermaceae) inferred from chloroplast and nuclear sequences. Perspect Plant Ecol Evol Syst 8: 141-154.

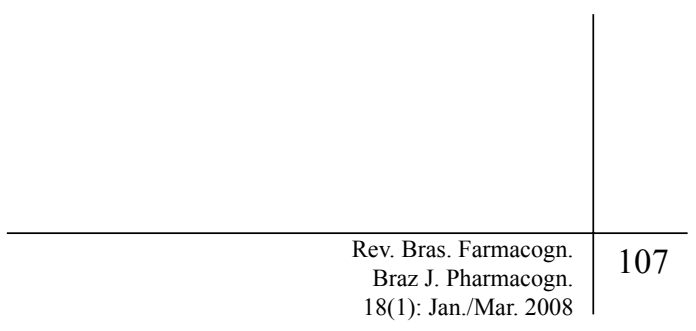

